\title{
Comparative experimental analysis of the effect caused by artificial and real induced damage in composite laminates
}

\author{
Marco A. Pérez ${ }^{\mathrm{a}, \mathrm{b}, *}$, Lluís Gil ${ }^{\mathrm{a}, \mathrm{b}}$, Montserrat Sanchez ${ }^{\mathrm{a}, \mathrm{b}}$, Sergio Oller ${ }^{\mathrm{b}, \mathrm{c}}$ \\ ${ }^{a}$ Laboratory for the Technological Innovation of Structures and Materials (LITEM), Colon 11, TR45, Terrassa, 08222 Barcelona, Spain \\ ${ }^{b}$ Departament de Resistència de Materials i Estructures a l'Enginyeria, Universitat Politècnica de Catalunya - BarcelonaTech, Spain \\ ${ }^{c}$ International Center for Numerical Methods in Engineering (CIMNE), Gran Capità s/n, Edifici C1, 08034 Barcelona, Spain
}

\begin{abstract}
This paper presents the results of an extensive experimental campaign aimed to examine the effect upon the vibration response and on the residual load-bearing capacity caused by both: isolated artificially induced interlaminar damage and low-velocity impact induced damage in composite laminates. The experimental programme included modal testing, drop-weight impact testing, ultrasonic inspection, transverse quasi-static loading testing and compression testing conducted on a set of 72 carbon fibre-reinforced composite laminated coupons. Both types of damage caused measurable changes in laminate performance, however marked divergent trends were observed. The results allowed for conclusions to be drawn regarding the adequacy of the artificial damage approach and highlighted the importance and role of other forms of degradation upon damage tolerance of laminated composites containing damage.
\end{abstract}

Keywords: Composite laminates, Low-velocity impact, Ultrasonic testing, Experimental modal analysis, Quasi-static loading, Compression after impact

\section{Introduction}

With the increasing use of composite materials in industry comes an increasing need of a better understanding of their behaviour and improving their performance. Over the years, a tremendous amount of activity has been devoted to developing accurate and fast non-destructive evaluation techniques as well as numerical methodologies, which can quantitatively predict the performance and durability of composite structures. This is due to the fact that composite materials represent a departure from the way that conventional materials are used, and, consequently, they require unconventional approaches to dealing with them.

During the last decades, a significant research effort has been particularly devoted to the study of impact and post-impact behaviour of laminate composite structures, since this is a phenomenon which has greatly hindered their widespread application. Experimental studies consistently indicate that impact induced damage is a mixture of three main failure modes: matrix cracking, delamination and fibre breakage, among which delamination the most severe because it may severely degrade the stiffness and strength of composite structures Reid and Zho (2000); Hodgkinson (2000). Consequently, several studies assessed and quantified composite damage resistance and damage tolerance in terms of delaminated area.

Numerous contributions have been made to numerically model the damage in composite materials Orifici et al. (2008).

\footnotetext{
${ }^{*}$ Corresponding author.

Email address: marco. antonio.perez@upc. edu (Marco A. Pérez)
}

Continuum damage mechanics approaches, which are based on material degradation models, have proved to be successful to predict different composite failure modes, including matrix cracking, delamination and fibre breakage Hinton et al. (2004). However, major efforts have been focused on the treatment of delamination Pagano and Schoeppner (2000): two common approaches are the virtual crack closure technique (VCCT) Krueger (2004) and the cohesive zone models (CZMs) Camanho et al. (2003); Lopes et al. (2009). In parallel, numerous experimental studies dealing with composite damage detection have also been published. It is notable that a large number of experimental works were based on the analysis of the influence of an isolated artificially induced damage Ooijevaar et al. (2010); Wei et al. (2004); Kessler et al. (2002); Yam (2004). It is common practice to induce delamination by inserting a polyimide film before consolidating a composite specimen in an autoclave.

As shown, the importance of delamination is well recognized. However, for the particular case of an impact, delamination does not occur in isolation. While numerous studies on the relationship between delamination and damage tolerance have been reported, little has been found in the literature concerning the role of other forms of damage, such as fibre breakage or indentation, in the residual load-bearing capacity. This issue could be addressed through numerical modelling. On the other hand, problems can arise when using an experimental approach since different damages are not always accounted for separately. One approach that may be worthy of consideration is the use an artificially embedded delamination, which allows the delamination-type of failure to be decoupled from the other ones. 
Bearing this in mind, the purpose of the present study was to deeply examine in-depth the effect upon the vibration response and on the residual load-bearing capacity caused by both: isolated artificially induced interlaminar damage and lowvelocity impact induced damage in composite laminates. According to the authors' knowledge, this topic has not been fully studied hitherto. This work enters in the continuity of the work conducted by the authors Pérez et al. (2014). This paper mainly presents the results of an extensive experimental campaign carried out on a set of 72 carbon fibre-reinforced composite laminated coupons. The experimental programme included modal testing, drop-weight impact testing, ultrasonic inspection, transverse quasi-static loading testing and compression testing. The results showed that both types of damage caused measurable changes in composite laminate performance. However, markedly divergent trends between experimental results of two types of damage were observed. The results allowed for conclusions to be drawn regarding the adequacy of the artificial approach and highlighted the importance and role of other forms of damage induced during the impact event.

In the following section, the methodology is described and details and requirements of the experimental test procedures are given. Subsequently, test results are presented, compared and discussed in section three. Finally, the conclusions of the study
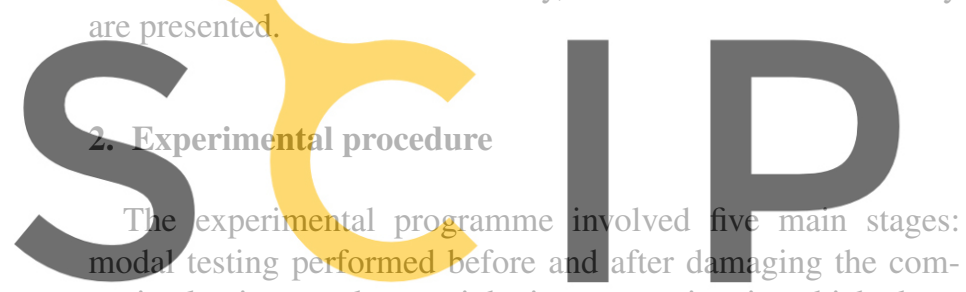

posite laminates, drop-weight impact testing in which damRegisters induced in a controlled manner, ultrasonic inspec-

and the extent of induced delaminations, and finally transverse quasi-static loading (QSL) tests and compression after impact (CAI) tests to assess the transverse and compressive residual bearing capacity of composite specimens, respectively.

\subsection{Test specimens}

The experimental programme was executed for a total of 72 monolithic composite plate specimens measuring $150 \times 100 \times 5.2$ $\mathrm{mm}^{3}$. In the manufacturing process, commercially available unidirectional prepreg laminae composed of carbon fibres ${ }^{1}$ (volume-fraction of $55.2 \%$ ) embedded in a resin epoxy matrix ${ }^{2}$ were used. The quasi-isotropic laminated plates were composed of 40 unidirectional laminae with a balanced and symmetric stacking sequence $\left[45^{\circ} / 0^{\circ} /-45^{\circ} / 90^{\circ}\right]_{5 S}$, resulting in a nominal thickness of approximately $5.2 \mathrm{~mm}$ with an uniform cross-section over the entire surface. The laminated plate layup was defined such that the $0^{\circ}$ fibre orientation was aligned with the lengthwise dimension. Laminate curing was performed following a standard autoclave procedure.

\footnotetext{
${ }^{1}$ Grafil TR30S 3K.

${ }^{2}$ Resin epoxy HSC Epikote 4652.
}

Among the samples manufactured, 48 of them were pristine specimens while 24 specimens were manufactured by inserting an artificially induced delamination -a circular geometry polyimide film- before consolidating the coupons in an autoclave. Diameters of 10, 20, 30, 40, 50 or $70 \mathrm{~mm}$ were embedded on the layers $5,10,15$ or 20 (see Table 1). After the curing process, pristine coupons were examined using non-destructive ultrasonic inspection to assess the grade of compaction and to discard the presence of defects, porosities or delaminations.

\subsection{Modal testing}

In order to obtain the modal parameters (frequencies and mode shapes) to examine the effect of the induced damage upon the vibration response, modal testing of the pristine and damaged composite laminates was performed. Tests were carried out under free boundary conditions by suspending the coupons vertically. The real-time sampled signals (excitation and response) were measured and recorded in form of time series and processed into inertance frequency response function (FRF) data. Vibration measurements were performed using a singlereference roving hammer test. A mono-axial accelerometer ${ }^{3}$ was attached to a single degree of freedom (DoF) reference point on the top surface of the laminate, whereas the miniature transducer hammer ${ }^{4}$ roved around, exciting the specimen

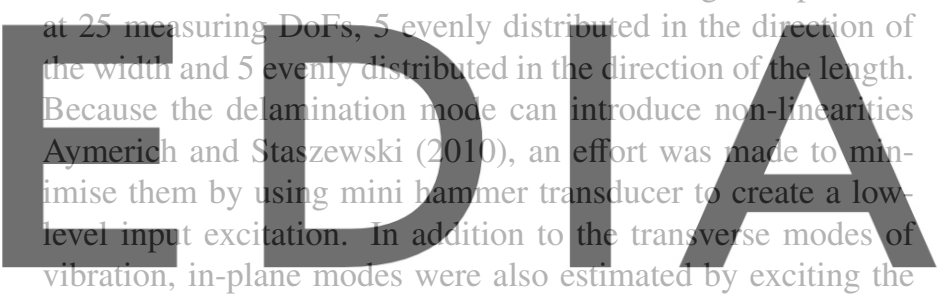
specimen at 5 evenly distributed locations on each lateral side.

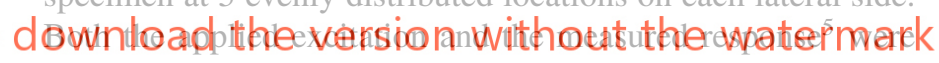
perpendicular to the coupon. Signals were averaged 3 times for each measurement point, and the test frequency band was up to $20 \mathrm{kHz}$ with a resolution of $3.125 \mathrm{~Hz}$.

\subsection{Drop-weight impact testing}

An ASTM ${ }^{6}$ D7136 standard test ASTM-D7136 (2007) was followed to determine the damage resistance of the laminated composite specimens subjected to a drop-weight impact event. The test procedure consisted in releasing a weight from a certain height, which determined the incident kinetic energy. A detailed description of the test conducted can be found in reference Pérez et al. (2013).

A total of 44 coupons were impacted with incident energy levels $\left(E_{I}\right)$ ranging from 6.6 to $70 \mathrm{~J}$, in intervals of $5 \mathrm{~J}$, with a minimum of 2 and maximum of 4 specimens tested for each impact energy. The lower limit was determined by the minimum height condition imposed by the standard test method. The upper limit was defined by considering a hypothetical energy level

\footnotetext{
${ }^{3}$ Accelerometer Bruel \& Kjaer 4518-003.

${ }^{4}$ Hammer Bruel \& Kjaer 8204.

${ }^{5}$ Data acquisition system Bruel \& Kjaer 3050-B-6/0.

${ }^{6}$ American Society for Testing and Materials.
} 
below both the penetration and perforation thresholds. The 4 remaining specimens were reserved to ensure the repeatability of modal testing and to determine the transverse and compressive bearing capacity of the pristine laminates.

\subsection{Ultrasonic testing}

The term state of damage implies knowledge of the type, extent and location of induced damage, and it is three-dimensional in nature. Ultrasonic phased array testing provides a precise through thickness damage information useful for determining the depth, size and distribution of internal delaminations. After the drop-weight impact test, the interlaminar damage onset was estimated and the extent of induced damage in impacted laminates coupons was measured by using non-destructive ultrasonic inspection equipment ${ }^{7}$. Using data from B and C-scan, depth and extent of the induced delaminations were determined in terms of projected area. Coupons with artificially embedded delamination were also examined to assess the accuracy of the equipment calibration.

\section{Quasi-static loading testing}

The transverse quasi-static loading testing (QSL) may be considered as a particular case of low-velocity impact. QSL test allows determining the transverse stiffness of pristine and

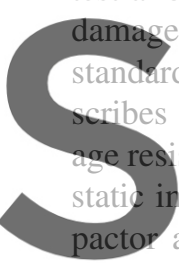
rd te
inde
as de test method ASTM D626
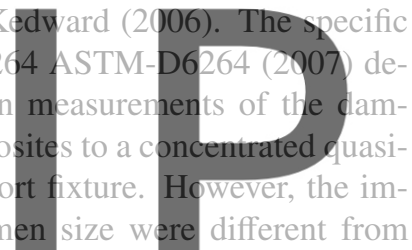
those outlined in ASTM D7136 ASTM-D7136 (2007) and D7137 ASTM-D7137 (2007). Accordingly the same support

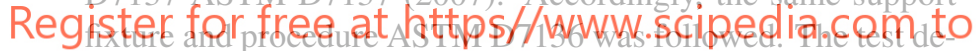
vice consisted of a plate-like fixing support with a rectangular and centered hole cut-out, upon which the sample was placed. The specimen was fixed by four horizontal toggle clamps ${ }^{8}$. The coupons were perpendicularly loaded ${ }^{9}$ up to failure with a cross-head displacement rate of $1.25 \mathrm{~mm} / \mathrm{min}$. Indentation force and plate central deflection data were recorded ${ }^{10}$ at a sampling rate of $500 \mathrm{~Hz}$.

QSL tests were performed first on 2 pristine coupons, then on a series of 12 damaged specimens at various impact energy levels ranging from 6.6 to $70 \mathrm{~J}$, and finally on 12 specimens with the artificially embedded delamination over the layers 5 or 15 (see Table 1).

\subsection{Compression after impact testing}

The compression after impact (CAI) test determines the compressive residual strength of flat rectangular composite plates previously subjected to an impact event. In the present study,

\footnotetext{
${ }^{7}$ OmniScan MX with standard phased array probe $5 \mathrm{MHz}$ linear array 64 elements.

${ }^{8}$ AMF model 6830-3.

${ }^{9} 250 \mathrm{kN}$ capacity MTS actuator model 244.31 .

${ }^{10}$ Data acquisition system HBM MGCplus.
}

the same test was employed to determine the residual loadbearing capacity of the specimens manufactured with the artificially embedded delamination. CAI tests were performed using the support fixture which meets the requirements of the standard test method ASTM D7137 outlined in ASTM-D7137 (2007).

The support fixture was carefully aligned to minimise loading eccentricities and specimen induced bending. The coupon was aligned with the lengthwise dimension and loaded with a cross-head displacement rate of $1.25 \mathrm{~mm} / \mathrm{min}$ until the maximum load was reached; the load was then reduced to a magnitude approximately $25 \%$ below the maximum. To ensure that the applied compressive load did not generate any bending moment on the plates, the strain distribution was monitored during the test. Three strain gauge ${ }^{11}$ pairs were bonded back-to-back on each side of the impacted coupons and one gauge was installed on one side of the coupons with artificially embedded delamination. Force, cross-head displacement and strain data was recorded. A detailed description of the test conducted can be found in references Pérez et al. (2014, 2012).

CAI tests were performed first on 2 pristine coupons, then on a series of 32 damaged specimens at various impact energy levels as described above, and finally on 12 specimens with the artificially embedded delamination over the layers 10 or 20 (see

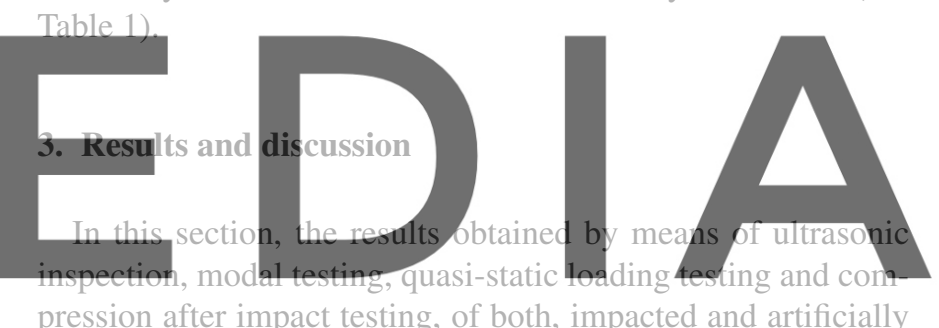

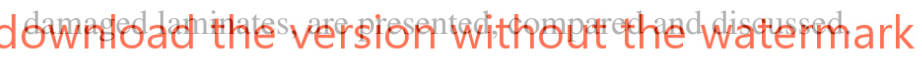

\subsection{Ultrasonic inspection}

Table 1 collects the characteristics of the manufactured laminated specimens with artificially embedded delamination (columns 2 to 4 ) as well as a summary of the experimental results of ultrasonic inspection (columns 5 to 7). As the extent and depth of the artificial damage were known, this procedure served to verify the experimental procedure and quantify the error. In most of the cases, the delaminated area identified presented good agreement with the prediction. Major differences arose in smaller size defects due to the resolution of the test. It should be noticed that some defects were not measured. This was because the length of the probe limited the inspection to defects below $60 \mathrm{~mm}$. On the other hand, the grade of compaction of the specimens 64/04L6 and 68/08L6 impeded proper inspection of these particular laminates. Errors for depth defect estimation were found to be \pm 1 layer.

The extent of the internal damage induced by a low-velocity impact, was determined according to the requirements of the standard test method ASTM D7136 ASTM-D7136 (2007).

\footnotetext{
${ }^{11}$ Strain gauge HBM 1-LY41-6/350.
} 
Table 1: Characteristics of the tested specimens with an artificially induced delamination and summary of the experimental results of ultrasonic testing.

\begin{tabular}{|c|c|c|c|c|c|c|}
\hline & \multicolumn{3}{|c|}{ Artificial delamination } & \multicolumn{2}{|c|}{ Ultrasonic testing } & Error \\
\hline Specimen & $\begin{array}{l}\text { Diameter } \\
(\mathrm{mm})\end{array}$ & $\begin{array}{c}\text { Area } \\
\left(\mathrm{mm}^{2}\right)\end{array}$ & Layer & $\begin{array}{c}\text { Area } \\
\left(\mathrm{mm}^{2}\right)\end{array}$ & Layer & $\begin{array}{c}\text { Area } \\
(\%)\end{array}$ \\
\hline 49/01L5 & 10 & 78.5 & 5 & 99.0 & 5 & 26.2 \\
\hline $50 / 02 \mathrm{~L} 5$ & 10 & 78.5 & 10 & 87.5 & 10 & 11.5 \\
\hline 51/03L5 & 10 & 78.5 & 15 & 89.0 & 15 & 13.4 \\
\hline $52 / 04 \mathrm{~L} 5$ & 10 & 78.5 & 20 & 74.8 & 20 & -4.7 \\
\hline 53/05L5 & 20 & 314.2 & 5 & 353.2 & 5 & 12.4 \\
\hline 54/06L5 & 20 & 314.2 & 10 & 338.1 & 11 & 7.6 \\
\hline 55/07L5 & 20 & 314.2 & 15 & 310.3 & 15 & -1.2 \\
\hline 56/08L5 & 20 & 314.2 & 20 & 326.6 & 19 & 3.9 \\
\hline 57/09L5 & 30 & 706.9 & 5 & 735.8 & 5 & 4.1 \\
\hline 58/10L5 & 30 & 706.9 & 10 & 677.2 & 11 & -4.2 \\
\hline 59/11L5 & 30 & 706.9 & 15 & 728.5 & 15 & 3.1 \\
\hline $60 / 12 \mathrm{~L} 5$ & 30 & 706.9 & 20 & 713.9 & 19 & 1.0 \\
\hline 61/01L6 & 40 & 1256.6 & 5 & 1281.1 & 5 & 1.9 \\
\hline $62 / 02 \mathrm{~L} 6$ & 40 & 1256.6 & 10 & 1246.4 & 10 & -0.8 \\
\hline 63/03L6 & 40 & 1256.6 & 15 & 1200.2 & 15 & -4.5 \\
\hline 64/04L6 & 40 & 1256.6 & 20 & N.A & & - \\
\hline 65/05L6 & 50 & 1963.5 & 5 & 1906.9 & 5 & -2.9 \\
\hline 66/06L6 & 50 & 1963.5 & 10 & 1905.1 & 11 & -3.0 \\
\hline 67/07L6 & 50 & 1963.5 & 15 & 1938.7 & 19 & -1.3 \\
\hline 68/08L6 & 50 & 1963.5 & 20 & N.A & - & - \\
\hline 69/09L6 & 70 & 3848.5 & 5 & N.A $A^{\dagger}$ & 5 & - \\
\hline 70/10L6 & 70 & 3848.5 & 10 & N.A $A^{\dagger}$ & 11 & - \\
\hline 71/11L6 & 70 & 3848.5 & 15 & N.A $A^{\dagger}$ & 16 & - \\
\hline $72 / 12 \mathrm{~L} 6$ & 70 & 3848.5 & 20 & N.A $A^{\dagger}$ & - & - \\
\hline
\end{tabular}

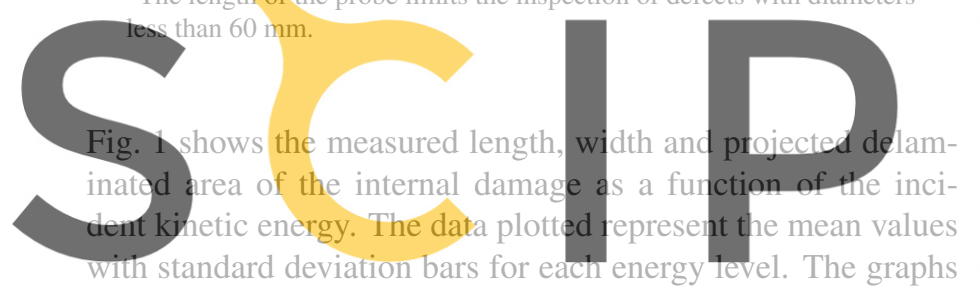

present indications that refer to the interlaminar damage onset

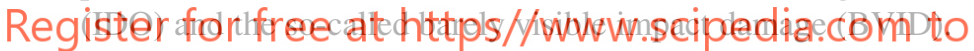

The former was set over $15 \mathrm{~J}$ of incident kinetic energy, the latter corresponds -according to industry standards- to the impact energy level that produces an indentation depth of $0.3 \mathrm{~mm}$ after relaxation.

Fig. 1 shows that while linear law predicts the low energy range, the estimated delaminated areas deviates from the linear behaviour as the energy increases, reaching an asymptotic value. This result stands in apparent contrast to those of previous publications Zou et al. (2002); Li et al. (2002). A possible cause may be that in the present work the incident energies range was significantly higher. In this sense, it is worth noting that -as experimentally ascertained- the change in slope corresponds with the onset of fibre breakage. Another important aspect to consider is the influence of the boundary conditions of the test device. This observation is in agreement with previous published studies Pérez et al. (2014); Gonzàlez et al. (2011).

\subsection{Frequency shifts}

Modal frequency shifts have been extensively used in the literature as a damage indicator for composites Yam (2004); Zou et al. (2000); Della and Shu (2007); Frieden et al. (2011). It is generally known that delamination decreases stiffness and, in turn, decreases modal frequencies. In the context of this

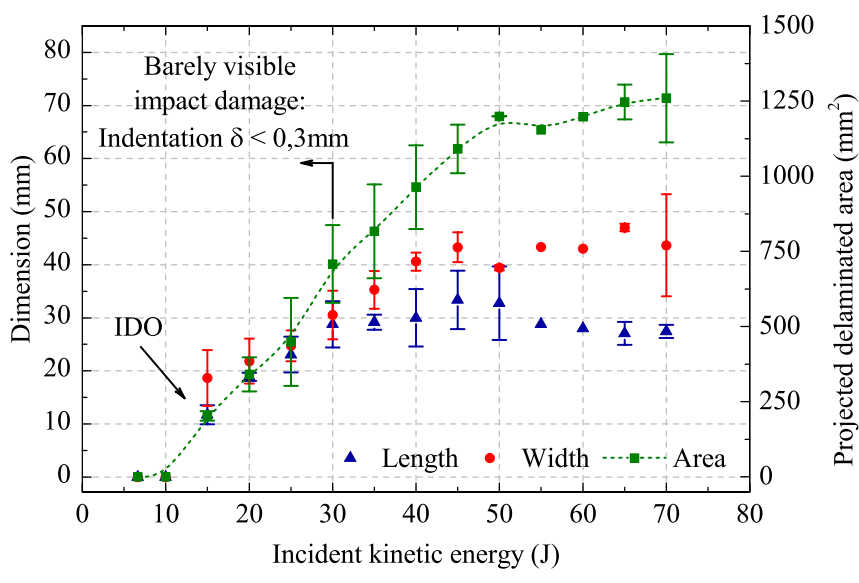

Figure 1: Ultrasonic testing results of the estimated length, width and projected delaminated area, as a function of incident kinetic energy. IDO refers to the interlaminar damage onset.

work, modal frequency shifts as a function of damage severity were examined for both, impacted and artificially damaged laminates.

Fig. 2 shows the percentage frequency changes as a function of the projected delaminated area of the first 12 transverse modes and first 3 in-plane modes. The results correspond to a comparison of the vibration response before and ffter dam-
aging the specimen. The data plotted represent nean values
with standard deviation bars for each energy level. In order to
clarify the plots, the x-axis is set to represent the mean values
of the projected delaminated area for each encrgy level. The
minimum number of modes estimated for each est specimen limits the number of transverse modes analysed to 12 , whereas dhe test frequency band limits the number of in-plane modes as was labelled according to its position in the frequency spectrum. The nomenclature $(a, b)$ identifies each different mode type, where $a$ and $b$ denote the number of nodal lines parallel to the crosswise and lengthwise direction, respectively.

Overall, the results show that the vibration response is correlated with the damage severity, indicating a decrease as the extent of induced damage increases. However, the magnitude of changes does not become significant until the projected delaminated area reaches $800 \mathrm{~mm}^{2}$. It is shown that a sudden drop of the frequency shift occurs after the $1100 \mathrm{~mm}^{2}$ value, which corresponds to the onset of fibre breakage. On the other hand, it is noted that not all modes are equally affected by the same damage level. The most significant variations are observed, in the 9th and 10th transverse modes and in the 23rd and 24th in-plane modes. Nonetheless, the maximum change is approximately estimated in 5\% for transversal modes and in $7 \%$ for in-plane modes.

Fig. 3 shows the percentage frequency changes as a function of the artificially embedded delaminated area and for each defect's depth, using the first 11 transverse modes and first 3 in-plane modes. The transverse mode $\left(\begin{array}{ll}0 & 3\end{array}\right)$ was not reliably identified in all tested specimens, wherefore it has not been included in the plots. The results correspond to a comparison of 

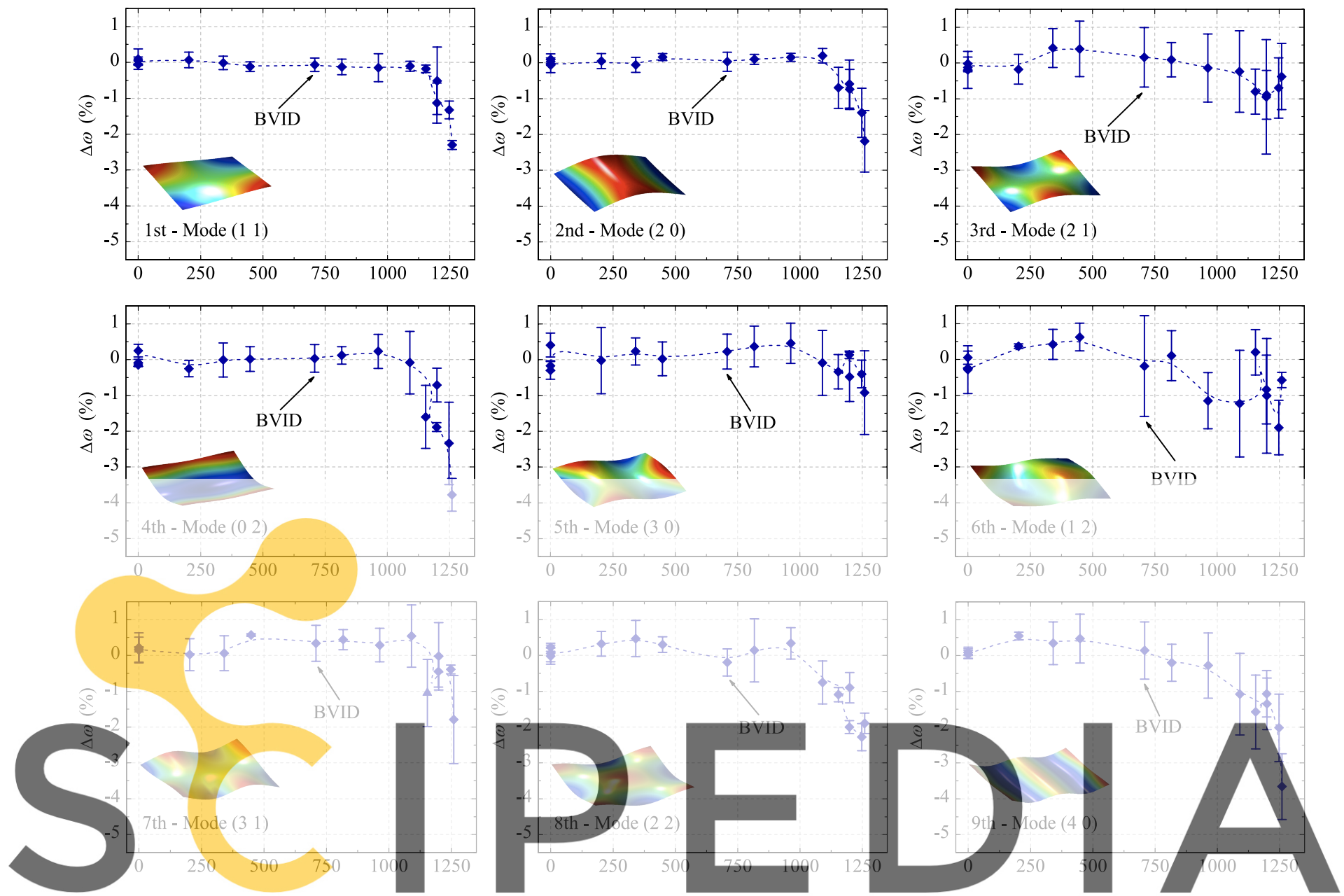

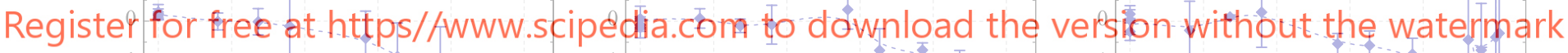
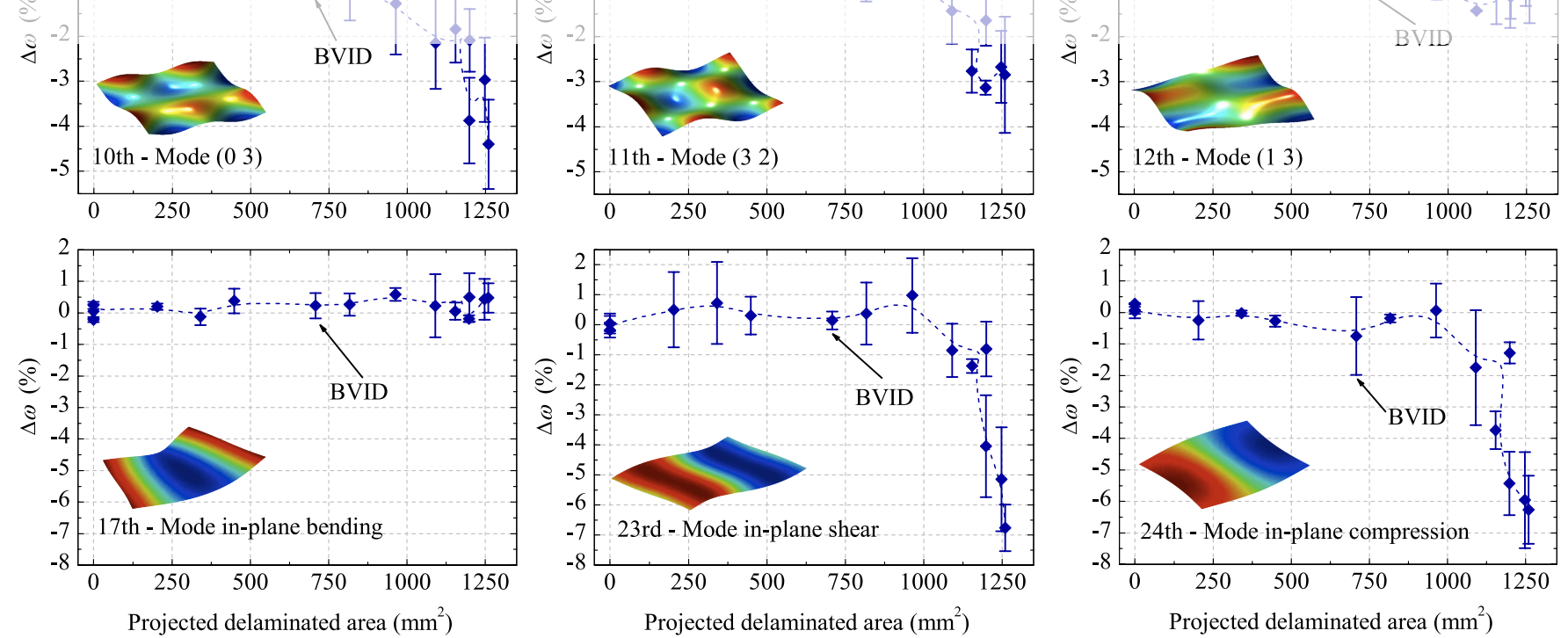

Figure 2: Percentage frequency changes as a function of the projected delaminated area of the first 12 transverse modes and first 3 in-plane modes. BVID refers to the so-called barely visible impact damage. 
the vibration response of the artificially damaged laminates and a pristine coupon. In general, the frequency shifts show a trend to decrease as the artificial damage size increases. As in the previous case, it can be observed that the differences are larger for higher transverse modes. In contrast, the frequencies of the in-plane modes remained almost unchanged within the range of the experimental error assumed. These differences can be attributed to the effect of fibre breakage, as it will be discussed afterwards.

In order to independently address the study of the influence of the defect size and the embedded layer, in Fig. 4 the percentage frequency shifts are represented in a different form, as a function of the artificially embedded delamination depth for each diameter's defect. The minimum changes in the in-plane modes and its independence from the damage's size are again observed. The most significant variations (with exception of the $70 \mathrm{~mm}$ delamination) are observed when artificial defects were embedded over the layers 5 and 20. The former is supposed to be due to resonance cavity created near the surface and the latter due to the decrease of the transverse stiffness.

In short, while the trend of the results derived from the artificially embedded delaminations proves an influence on the vibration response, hinders the recognition of a conclusive behaviour pattern.

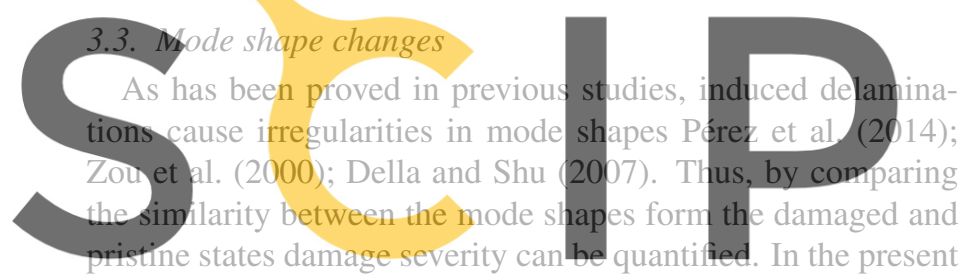
work, this was addressed firstly by using the Modal Assurance

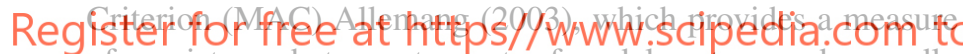
of consistency between two sets of modal vectors, and secondly by using the PrMAC criterion Pérez et al. (2014), which transforms the MAC information into a scalar value. It is defined as follows:

$$
\operatorname{PrMAC}\left({ }^{d} \boldsymbol{\Phi}, \boldsymbol{\Phi}\right)=\prod_{i=1}^{m} \frac{\left|{ }^{d} \boldsymbol{\phi}_{i}^{t} \cdot \boldsymbol{\phi}_{i}\right|^{2}}{{ }^{d} \boldsymbol{\phi}_{i}^{t} \cdot{ }^{d} \boldsymbol{\phi}_{i} \boldsymbol{\phi}_{i}^{t} \cdot \boldsymbol{\phi}_{i}}
$$

where ${ }^{d} \boldsymbol{\Phi}$ and $\boldsymbol{\Phi}$ are the two sets of $m$ modal vectors and ${ }^{d} \boldsymbol{\phi}$ and $\phi$ are estimated from the damaged and pristine states, respectively.

The computation of MAC results in a square $m-$ by $-m$ diagonal matrix, being $m$ the number of modal vectors estimated. Its diagonal values are bounded between zero and one, where a value of one signifies perfect consistency and a low value indicates discordance between the sets of modal vectors. Fig. 5 collects the results of the diagonal MAC matrix mean values corresponding to the transverse modes correlation, as a function of the incident kinetic energy (left) and for each coupon with embedded delamination (right), respectively. Overall, a decrease of the correlation coefficients is observed as both damage sizes (real and artificial) increases. It is noted that changes are of a greater magnitude for the artificially induced damage specimens, being more significant on higher modes (as these modes are associated with local responses), even for the samples with smaller embedded defects.

Fig. 6 shows the comparison of the results of PrMAC coefficients corresponding to the first four transverse modes correlation, of both, impacted and artificially damaged laminates. Comparison is done in terms of the projected delaminated area. Regarding the impact induced damage results and despite the dispersion, a clear decreasing trend with an increasing amount of damaged area is shown. It is remarkable that in the initial region -corresponding to the pristine and nearly pristine statesthe PrMAC values differ from unity. This result is due to the inherent experimental error. On the other hand, although curves from artificially damaged laminates exhibit similar trends, deviations from the former are evident.

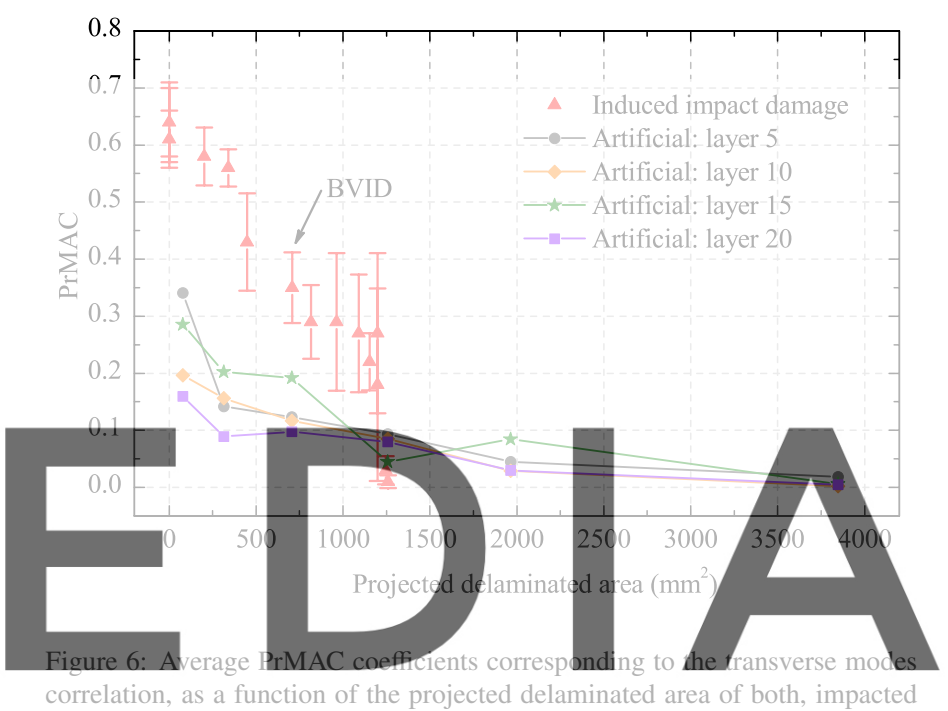
and artificially damaged laminates.

download the version without the watermark

As stated in section 3.2 and according to the results exposed, both types of damage have an influence on the vibration response. Nonetheless, the behaviour clearly diverges, being the artificially embedded delaminations those which cause greater changes.

\subsection{Transverse load-bearing capacity}

The quasi-static loading testing (QSL) allowed the evaluation of the transverse stiffness of both, impacted and artificially damaged laminates. Following impact tests, 2 pristine and 12 impact-damaged coupons were QSL tested to failure. The contact force versus midspan deflection curves obtained in QSL test are shown at Fig. 7. Comparison of the pristine and damaged specimens load-displacement curves show that the pristine coupons suffer two load drops, while impact-damaged coupons suffers only one. The first drop indicates the onset of delamination beyond which the material reloads, while the second corresponds to the maximum load encountered during QSL testing. The initial non-linear stiffness behaviour can be attributed to the contact stresses between the impactor and the specimen and to the indentation created in the specimen surface. The decreased gradient of the slope with increasing the amount of induced damage is apparent. This is attributed to the induced 

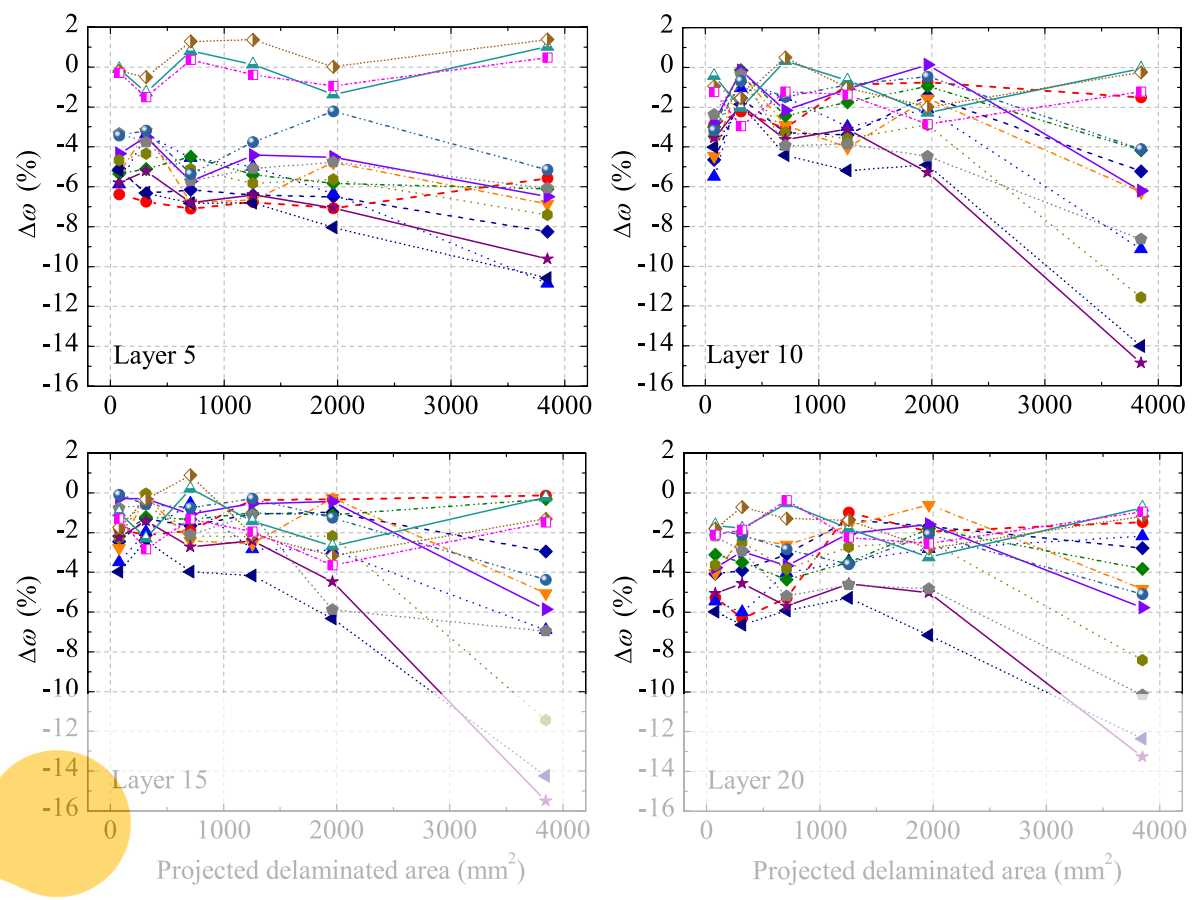

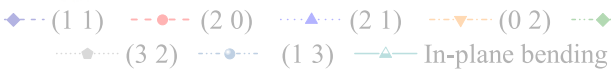

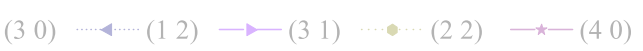

In-plane shear ……........ In-plane compression
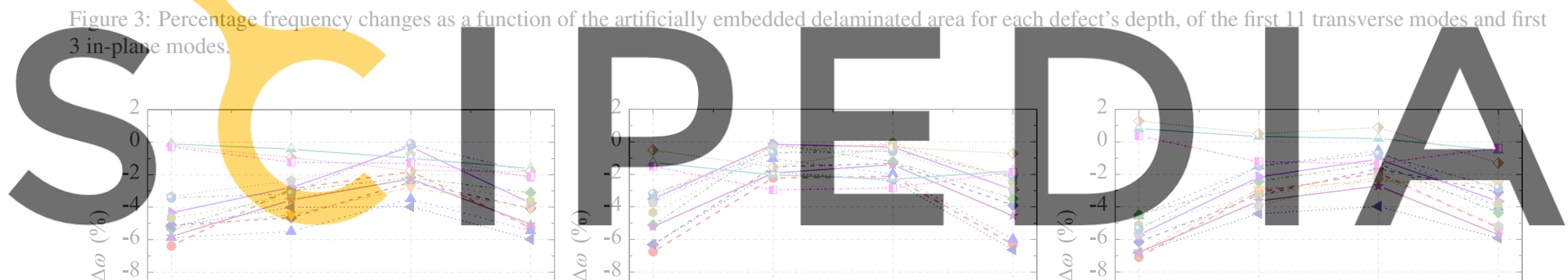

Register for free at https//www.scipedia.com to download the version without the watermark
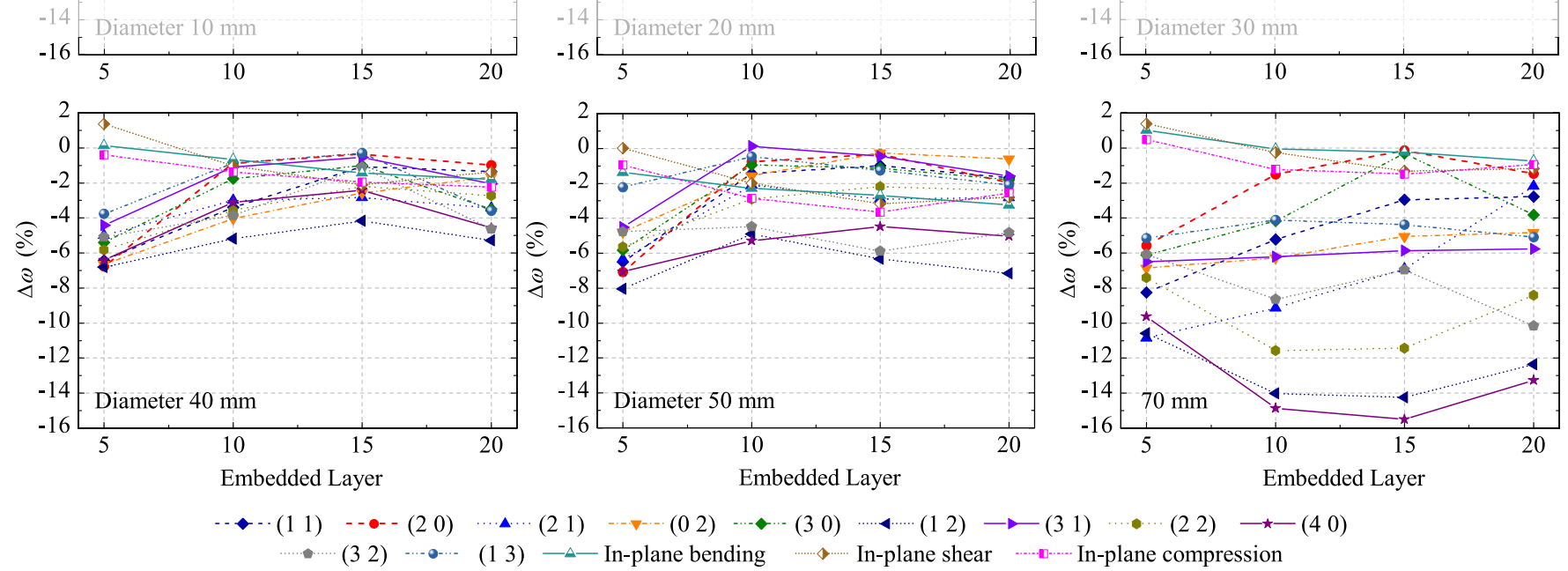

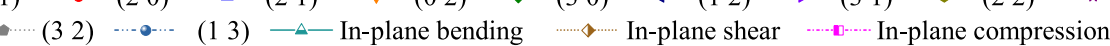

Figure 4: Percentage frequency changes as a function of the artificially embedded delamination depth for each diameter's defect, of the first 11 transverse modes and first 3 in-plane modes.

delamination, which conforms to previously published findings Feraboli and Kedward (2006).
Transverse stiffness values were determined for both, impacted and artificially damaged laminates, taking the slope of 

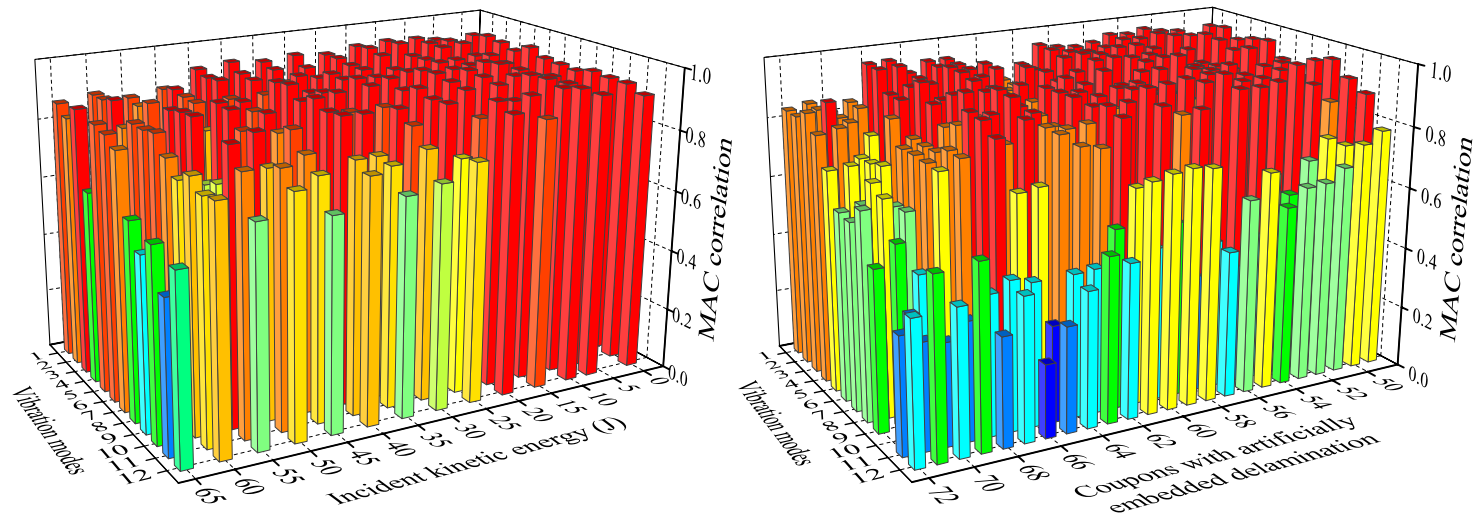

Figure 5: Average diagonal MAC matrix coefficients corresponding to the transverse modes correlation, as a function of the incident kinetic energy (left) and for each coupon with embedded delamination (right).

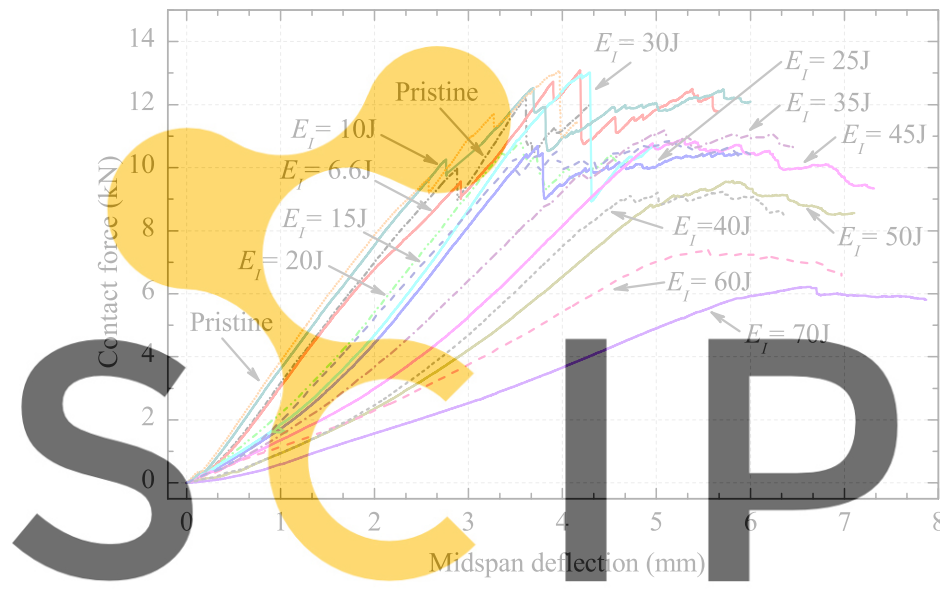

Figure 7: Contact force versus midspan deflection curves produced by a QSL

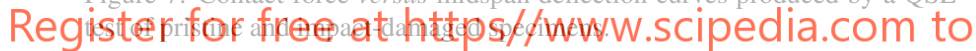

the data between $20 \%$ and $50 \%$ of the critical or maximum reached load. Fig. 8 collects the results of the transverse stiffness values estimated for tested coupons containing both types of damage, as a function of projected delaminated area. Results show a systematic decrease of transverse stiffness with increasing induced damage size. Nevertheless, markedly divergent trends between the two types of damage are observed. Regarding the impact induced damage results, notable differences arise beyond the BVID level. In this sense, it is worth noting that visual observations made after the impact tests to those specimens, revealed matrix cracking on the bottom opposite surface due to bending stress. The onset of fibre breakage was set of around $1100 \mathrm{~mm}^{2}$ of damage area. Concerning to the plotted results of the artificially damaged specimens, the upper values of the matched pairs correspond to those coupons manufactured with the artificially embedded delamination over the layer 15 , and the lower values correspond to those coupons with embedded delamination over the layer 5 . The numbering is set from the bottom opposite face (layer 1) to the top face of load application (layer 40). Closer examination reveals the influence of the artificial delamination depth upon to the transverse load-bearing capacity, with the effect being more adverse when defect is farther from the neutral axis in the bottom direction.

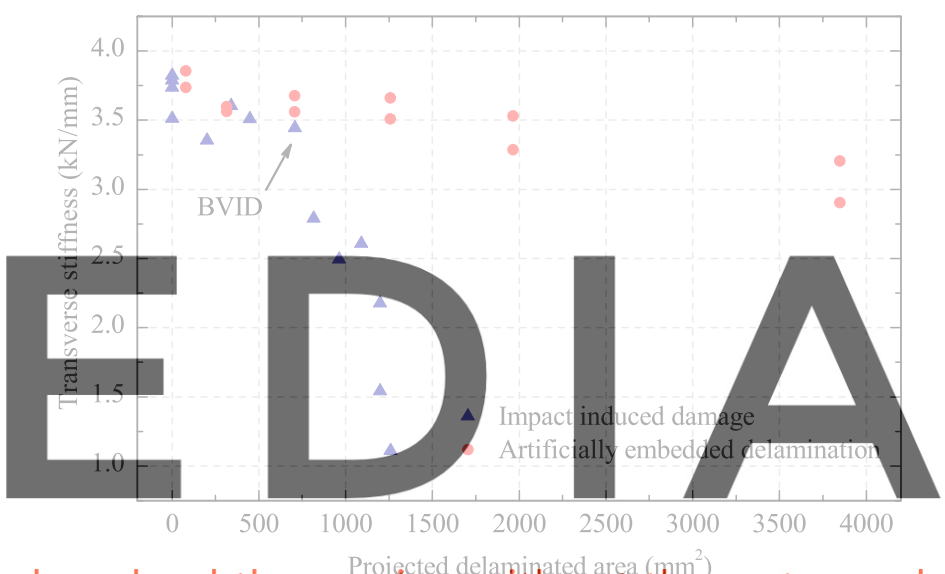

download the version without the watermark

Figure 8: Transverse stiffness values as a function of the projected delaminated area of both, impacted and artificially damaged laminates.

\subsection{Compressive load-bearing capacity}

Analogously to the previous section, results from CAI tests comparing damage tolerance of coupons containing both types of damage are reported. Fig. 9 shows two consecutive frames from a high speed video recording (1980 frames $\mathrm{s}^{-1}$ ) of two damaged laminate coupons during the CAI test. The top subfigure shows a specimen impacted at $15 \mathrm{~J}$ while the bottom one shows specimen 66/06L6 containing a $50 \mathrm{~mm}$ artificial delamination embedded over the layer 10. In this latter is possible to discern the artificial defect on the surface. Both frames on the left depict the instant prior to collapse in which the measured stress and strain values were $315 \mathrm{MPa}$ and $8388 \mu \mathrm{m} / \mathrm{m}$ for the impacted coupon, and $340 \mathrm{MPa}$ and $8877 \mu \mathrm{m} / \mathrm{m}$ for the artificially damaged coupon. Frames on the right depict the instant of the collapse, in which differences between the two types of laminates are observed. While in the former the crack propagated horizontally towards the support fixture for approximately $930 \mathrm{~ms}$, in the latter collapse occurred suddenly. 


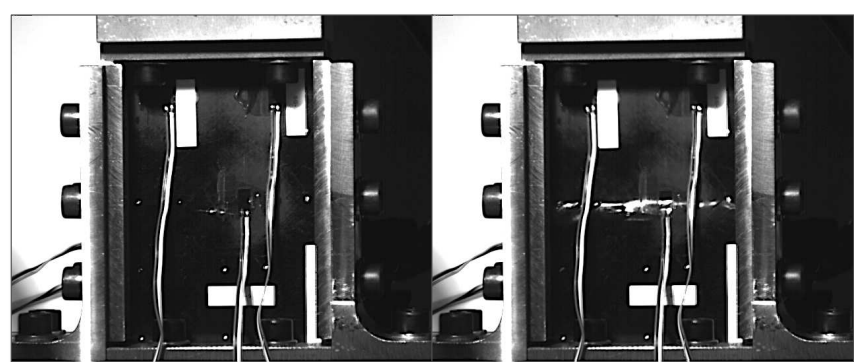

Frame 144 -17,9 [ms] / 1968 Hz, $505[\mu \mathrm{s}]$ Frame $145-17,4$ [ms] / 1968 Hz, $505[\mu \mathrm{s}]$
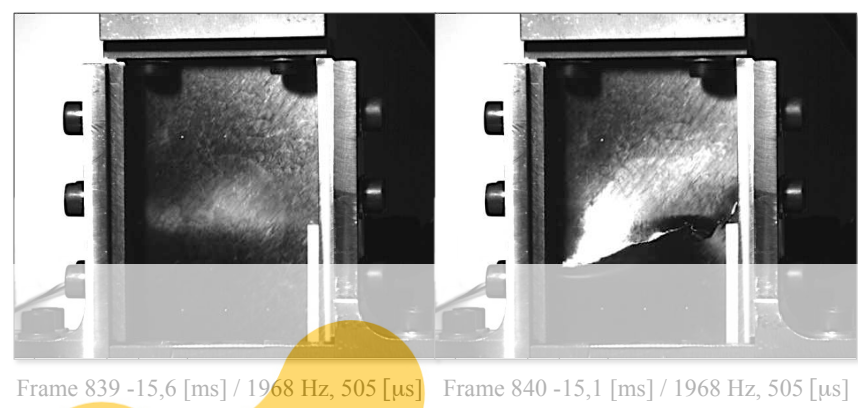

Figure 9: Consecutive frames from a high speed video recording during the CAI test, of a specimen impacted at $15 \mathrm{~J}$ (top) and specimen 66/06L6 containing a $50 \mathrm{~mm}$ artificial delamination embedded over the layer 10 (bottom).
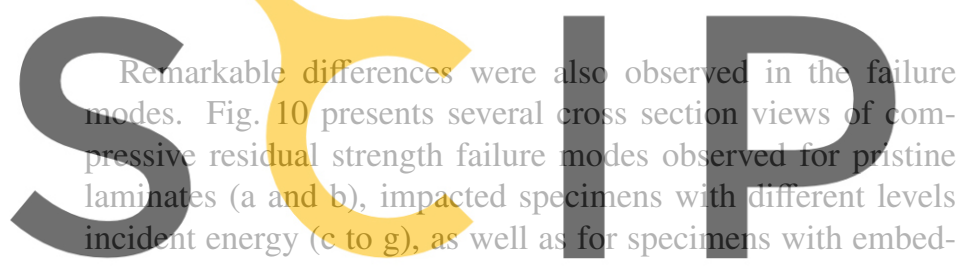

ded delamination ( $h$ to $j$ ). Among them and according to the standard test method ASTM D7137 outlined in ASTM-D7137

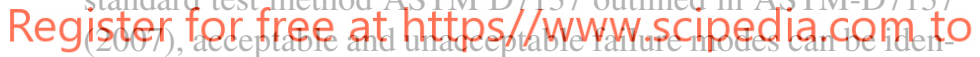

tified. Unacceptable failure modes are those related to load introduction by the support fixture, local edge support conditions or specimen instability (Fig. 10 (a, b, c, e and j)). In particular, failures of coupons a, c and d were related to a compressionshear effect while the failure of coupon c was related to load introduction by the support fixture and local edge support conditions. Thus, valid strength and strain results were only reported when appropriate failure modes were observed, such as the formation of kink bands due to fibre instability (microbuckling) (Fig. 10 ( $\mathrm{d}$ and $\mathrm{f}$ to $\mathrm{i}$ )). During the tests, support fixture was carefully aligned and the strain measurements remained linear and did not indicate panel instability. Striking differences on the failure modes can be observed between laminates containing the two types of damage. The formation of the kink-bands can be identified on both (see Fig. 10). However in the artificially damaged coupons these were not symmetric with respect to the midplane. Moreover, in the latter, the propagation of the interlaminar damage through the laminate was clearly visible, being possible to reliably discern the layer where the embedded defect was located.

On common procedures used to evaluate impact damage tolerance, it is common practice to relate test parameters, such as incident o dissipated energy, with residual bearing capac- ity estimated through the CAI test. However, this method did not allow to determine whether the residual behaviour of the laminate is dominated by impact damage resistant or by resistance to interlaminar damage propagation during compression test. Therefore, uncoupling of both resistances was required. To this end, the initial hypothesis that a relation exists between damage tolerance -in particular residual bearing capacity- and delaminated area, was adopted. Previous studies proved that interlaminar damage propagates transversely to loading direction Reis and Freitas (1997); Freitas and Reis (1998), as experimentally ascertained through high speed video recording. For this reason, in the present study, the width of delamination was considered as a representative parameter to compare damage tolerance between two laminates, irrespective of its impact damage resistance.

Fig. 11 collects the results of the superposition of ultimate compressive residual strength and average strain at failure of tested composite coupons, of both, impacted and artificially damaged laminates, as a function of the width of delamination. CAI tests were performed on damaged coupons as well as on pristine coupons. It should be noted that straight lines have been plotted in order to illustrate trends more clearly and hence do not correspond to a linear regression of the data. Dashed area illustrates the impact damage energy range lower than the

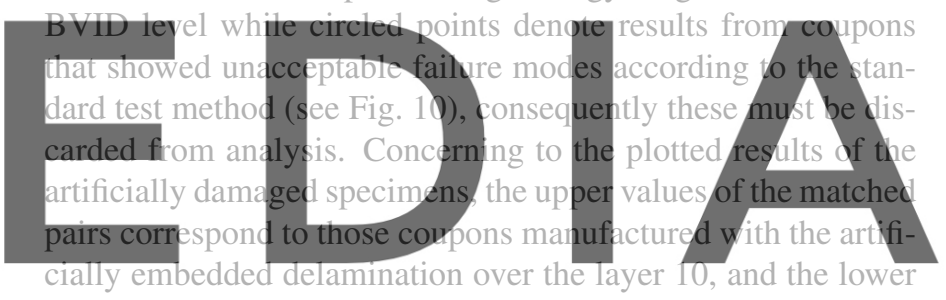
values correspond to those coupons with embedded delamina-

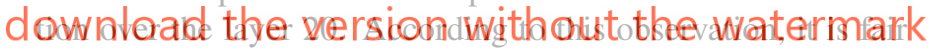
to assume that the artificial delamination depth had an influence upon the compressive load-bearing capacity, being more adverse when defect is located in the middle.

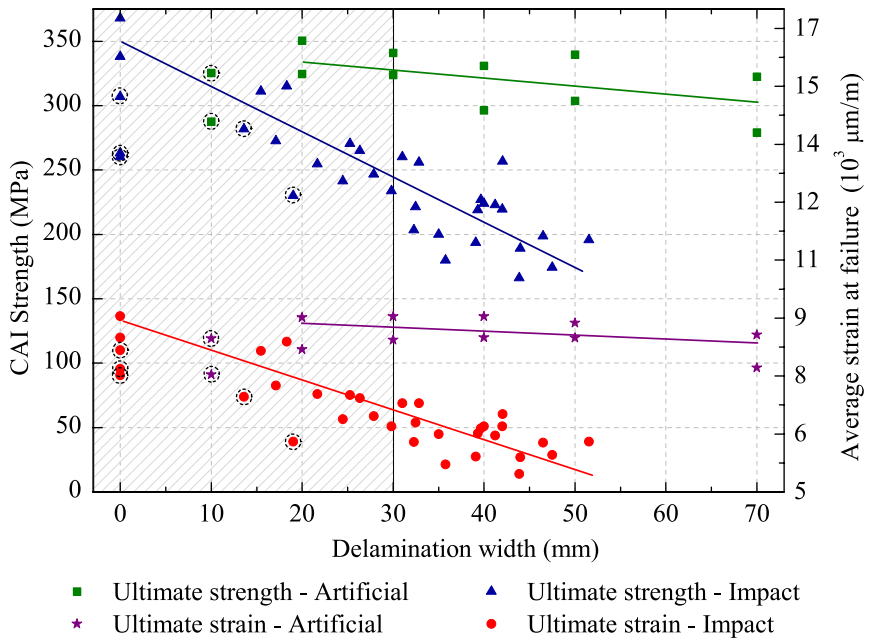

Figure 11: Results of compressive residual strength and strain at failure of tested coupons of both, impacted and artificially damaged laminates, as a function of the width of delamination. 


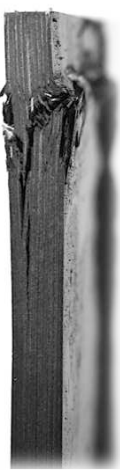

Pristine

(a)

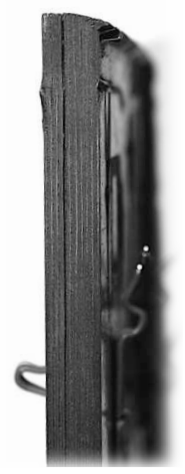

Pristine

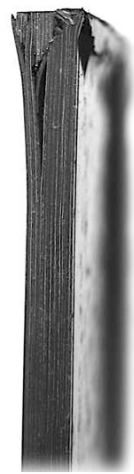

$E_{I}=6.6 \mathrm{~J}$

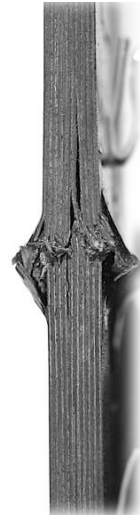

$E_{I}=15 \mathrm{~J}$

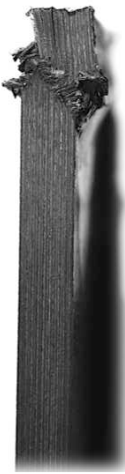

$E_{I}=20 \mathrm{~J}$

(e)

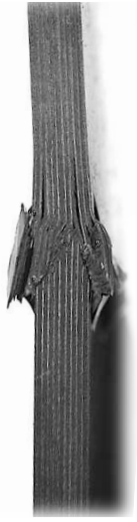

$E_{I}=25 \mathrm{~J}$

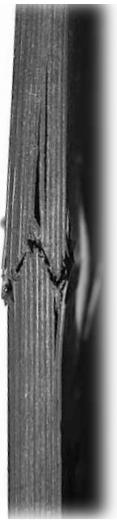

$E_{I}=65 \mathrm{~J}$

(g)
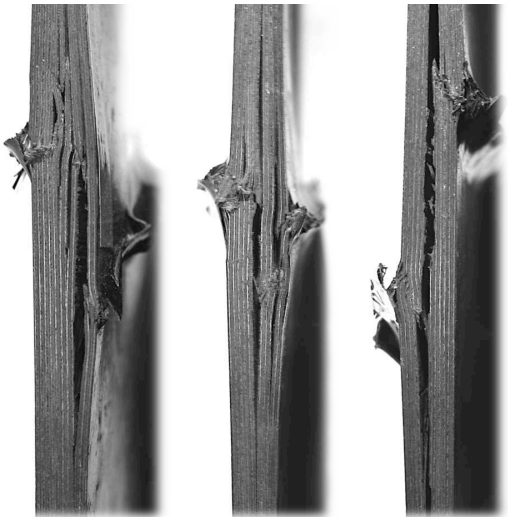

66/06L6/D50E10 68/08L6/D50E20 72/12L6/D70E20

(h)

(i)

Figure 10: Cross section view of compressive residual strength failure modes observed for pristine specimens (a and b), impacted specimens with different levels incident $\left(E_{I}\right)$ energy (c to g), as well as for specimens with embedded delamination (h to j). a, b, c, e and j coupons showed unacceptable failure modes.

Overail data plotted show a decreasing trend as width of delamination increases. Nevertheless, markedly divergent trends between two types of damage are observed, being the impacted coupons which exhibit a major decrease of its residual compressive strength. The present findings suggest that these dif-

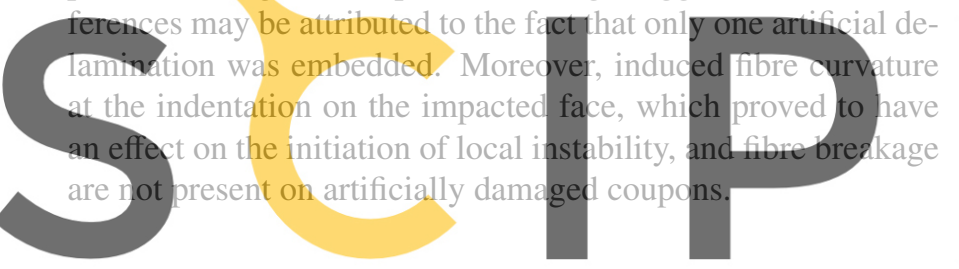

4. Conclusions

Register for free at https//www.scipedia.com to on a set of composite laminates coupons containing artificially induced interlaminar damage and low-velocity impact induced damage were presented and discussed. In order to determine the effect caused by the presence of both types of damage upon the vibration response and on the residual load-bearing capacity, modal testing, drop-weight impact testing, ultrasonic inspection, transverse quasi-static loading testing and compression testing have been conducted.

While the availability of a single specimen with unique artificial damage conditions bounds the study, some general and relative conclusions can be drawn regarding the effect of artificially induced damage. Overall, the results showed that both, the vibration response as well as the residual load-bearing capacity were correlated with the damage severity. Nevertheless, markedly divergent trends between two types of induced damage were observed.

From the analysis of the influence of single embedded delamination, experimental evidences indicate that delamination depth has an influence upon transverse and compressive loadbearing capacity, showing a trend to decrease as the artificial damage size increases. The effect was more adverse when defect was located farther from the neutral axis in the former case (QSL), and when defect was located in the middle in the latter case (CAI). Regarding the influence on the vibration response, experimental results hinder the recognition of a conclusive behaviour pattern. When comparing the influence of both types of damages, experimental results revealed that artificial damage caused major changes on the vibration response than those induced by impact damage. In contrast, its influence upon dam-
age tolerance proved not be as significant as real inapact dam-
age.
Finally, fibre breakage showed to have a significart effect on
the vibration response as well as on the transverde stiffness. On
the other hand, induced fibre curvature at the indentation on the impacted face, proved to have an effect on the initiation of local instability prior to laminate collapse during CAI testing.

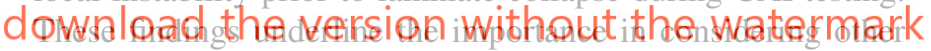
forms of damage apart from delamination failure when studying laminate structural degradation.

\section{Acknowledgements}

This work has been supported by the Spanish Ministry of Science and Innovation through RECOMP project ref. BIA200506952 and DELCOM Project ref. MAT2008-02232/MAT, by the Spanish Ministry of Public Works (project "Retrofitting and reinforcement of reinforced concrete structures with composite materials. Numerical and experimental developments applied to joint of bars and composites anchorage proposal"), by AIRBUS (Spain) through the Contract No. PBSO-13-06 FEMCOM and ACCIONA Infraestructuras (Spain) through the project SPHERA. All these support are gratefully acknowledged. Special thanks also to Roger Serra for useful discussions.

\section{References}

S. R. Reid, G. Zho, Impact behaviour of fibre-reinforced composite materials and structures, CRC Press, 2000.

J. M. Hodgkinson, Mechanical testing of advanced fibre composites, CRC Press, 2000. 
A. Orifici, I. Herszberg, R. Thomson, Review of methodologies for composite material modelling incorporating failure, Compos Struct 86 (2008) 194-210. Fourteenth International Conference on Composite Structures (ICCS/14).

M. Hinton, A. Kaddour, P. Soden, Failure criteria in fibre-reinforced-polymer composites, Elsevier, 2004.

N. Pagano, G. Schoeppner, Delamination of polymer matrix composites: Problems and assessment, in: A. Kelly, C. Zweben (Eds.), Comprehensive Composite Materials, Pergamon, Oxford, 2000, pp. 433-528.

R. Krueger, Virtual crack closure technique: history, approach and applications, Appl. Mech. Rev. 57 (2004) 109-143.

P. Camanho, C. Dàvila, M. De Moura, Numerical simulation of mixed-mode progressive delamination in composite materials, J. Compos. Mater. 37 (2003) 1415-1438.

C. Lopes, P. Camanho, Z. Gürdal, P. Maimí, E. Gonzàlez, Low-velocity impact damage on dispersed stacking sequence laminates. Part II: Numerical simulations, Compos Sci Technol 69 (2009) 937-947.

T. Ooijevaar, R. Loendersloot, L. Warnet, A. de Boer, R. Akkerman, Vibration based Structural Health Monitoring of a composite T-beam, Compos Struct 92 (2010) 2007-2015.

Z. Wei, L. H. Yam, L. Cheng, Detection of internal delamination in multi-layer composites using wavelet packets combined with modal parameter analysis, Compos Struct 64 (2004) 377-387.

S. S. Kessler, S. M. Spearing, M. J. Atalla, C. E. Cesnik, C. Soutis, Damage detection in composite materials using frequency response methods, Compos B Eng 33 (2002) 87-95.

L. H. Yam, Nondestructive Detection of Internal Delamination by Vibrationbased Method for Composite Plates, J Compos Mater 38 (2004) 2183-2198.

F. Aymerich, W. J. Staszewski, Impact damage detection in composite laminates using nonlinear acoustics, Compos Part A Appl Sci Manuf 41 (2010) 1084-1092.

ASTM-D7136, Standard test method for measuring the damage resistance of a fibre-reinforced polymer matrix composite to a drop-weight impact event, Tech. rep. West Conshohocken (PA, USA): American Society for Testing and Materials (ASTM), 2007.

M. A. Pérez, X. Martínez, S. Oller, L. Gil, F. Rastellini, F. Flores, Impact damage prediction in carbon fiber-reinforced laminated composite using the matrix-reinforced mixing theory, Compos Struct 104 (2013) 239 - 248.

P. Feraboli, K. T. Kedward, A new composite structure impact performance assessment program, Compos Sci Technol 66 (2006) 1336-1347.

ASTM-D6264, Standard Test Method for Measuring the Damage Resistance of a Fiber-Reinforced Polymer-Matrix Composite to a Concentrated QuasiStatic Indentation Force, Tech. rep. West Conshohocken (PA, USA): American Society for Testing and Materials (ASTM), 2007.

ASTM-D7137, Standard Test Method for Compressive Residual Strength Properties of Damaged Polymer Matrix Composite Plates, Tech. rep. West Conshohocken (PA, USA): American Society for Testing and Materials (ASTM), 2007.

M. A. Pérez, L. Gil, S. Oller, Impact damage identification in composite laminates using vibration testing, Compos Struct 108 (2014) 267 - 276.

M. A. Pérez, L. Gil, S. Oller, Evaluación del daño por impacto en laminados de material compuesto mediante la respuesta dinámica (in Spanish), CIMNE, 2012.

Z. Zou, S. Reid, S. Li, P. Soden, Application of a delamination model to laminated composite structures, Compos Struct 56 (2002) 375-389.

C. Li, N. Hu, J. Cheng, H. Fukunaga, H. Sekine, Low-velocity impact-induced damage of continuous fiber-reinforced composite laminates. Part II. Verification and numerical investigation, Compos Part A Appl Sci Manuf 33 (2002) 1063-1072.

E. Gonzàlez, P. Maimí, P. Camanho, C. Lopes, N. Blanco, Effects of ply clustering in laminated composite plates under low-velocity impact loading, Compos Sci Technol 71 (2011) 805-817.

Y. Zou, L. Tong, G. P. Steven, Vibration-Based Model-Dependent Damage (Delamination) Identification and Health Monitoring for Composite Structures: a Review, J Sound Vib 230 (2000) 357-378.

C. N. Della, D. Shu, Vibration of Delaminated Composite Laminates: A Review, Appl Mech Rev 60 (2007) 1-20.

J. Frieden, J. Cugnoni, J. Botsis, T. Gmür, Vibration-based characterization of impact induced delamination in composite plates using embedded FBG sensors and numerical modelling, Compos B Eng 42 (2011) 607-613.

R. J. Allemang, The modal assurance criterion: twenty years of use and abuse,
Sound and Vibration 37 (2003) 14-23.

L. Reis, M. D. Freitas, Damage growth analysis of low velocity impacted composite panels, Composite Structures 38 (1997) 509-515.

M. D. Freitas, L. Reis, Failure mechanisms on composite specimens subjected to compression after impact, Composite Structures 42 (1998) 365-373. 